\title{
Malignant fibrous histiocytoma producing spinal cord compression
}

\author{
P. J . T E D D Y A N D M . M E S I R I \\ From the Departments of Neurological Surgery and Neuropathology, The Radcliffe Infirmary, Oxford
}

SUMMARY Three cases of malignant fibrous histiocytoma presented as primary paraspinal tumours causing extradural spinal cord compression. Study of these cases suggests that pain relief is considerable after laminectomy but pain may recur with further tumour growth. Total removal is unrealistic and diagnosis difficult. The prognosis in terms of continuing neurological deficit after surgery followed by local radiotherapy appears poor.

Malignant fibrous histiocytoma represents one form of a group of tumours derived from the tissue histiocyte. It has been described as occurring chiefly in the soft tissues of the limbs and in the retroperitoneum. Two cases have been reported in which spinal nerve roots were infiltrated with tumour but we have been unable to find previous reports of these tumours occurring primarily in paraspinal tissues and presenting with features typical of extradural spinal cord compression. Three such cases are described, and the difficulty of distinguishing the lesions from granulomatous conditions and lymphoreticular neoplasms is emphasised.

\section{Case reports}

\section{CASE 1}

This 52 year old farmer (NW, RI No. 652628) had lost $12.7 \mathrm{~kg}$ in weight over the year before admission, and for eight weeks had experienced pain in his lumbar spine radiating round the abdomen and into both hips. He then developed weakness of both legs and, 10 days before admission, total constipation and retention of urine.

Examination revealed a cachectic man, tender over the lower thoracic spine. He had a complete spastic paraplegia with impaired sensation to pinprick and light touch below T11 dermatome and complete loss of joint position and vibration sense below the hips. There was no sacral sparing and there were no other abnormal findings on general examination.

Address for reprint requests: Mr P. J. Teddy, Department of Neurosurgery, The Radcliffe Infirmary, Oxford OX2 6HE.

Accepted 12 March 1979
Routine investigations were normal apart from an ESR of $32 \mathrm{~mm} / \mathrm{hr}$. Chest radiography showed no abnormality, but plain films of the thoracic spine showed destruction of T10 and T11 vertebral bodies. A myelogram showed a complete block to the contrast material at T11 vertebra. Decome pressive laminectomy on 17 August 1976 reveale extensive extradural tumour between $\mathrm{T} 10$ and $\mathrm{T} 12 \mathrm{C}$ vertebrae involving the laminae and paraspinak $\frac{\mathbb{D}}{0}$ muscles and extending round the anterior aspecB of the dura mater. The malignant tissue was bio opsied but no further removal attempted. Histoo logical examination of the biopsy material showe it to be a malignant fibrous histiocytoma.

The patient, although free from pain, regained neither the use of his legs nor sphincters, and he refused radiotherapy treatment. He gradually deteriorated and died six months later. The postmortem findings were those of malignant fibrous histiocytoma in the retroperitoneal and extradural spaces causing severe compression of the spinal cord maximal at L1-2 segments (Fig. 1). There were secondary deposits in the lungs, mesentery, and peritoneum. He also had pyelonephritis and bronchopneumonia.

CASE 2

This 45 year old female medical receptionist (JG, RI No. 678332) suffered upper abdominal and loin pains radiating down the back of both legs for over a year. In July 1977, a myelogram at another hospital was said to show a prolapsed intervertebral disc at L4/5 interspace, and she underwent laminectomy for removal of this disc. Postoperatively her back pain increased, with an acute exacerbation two months later. This was accom- 


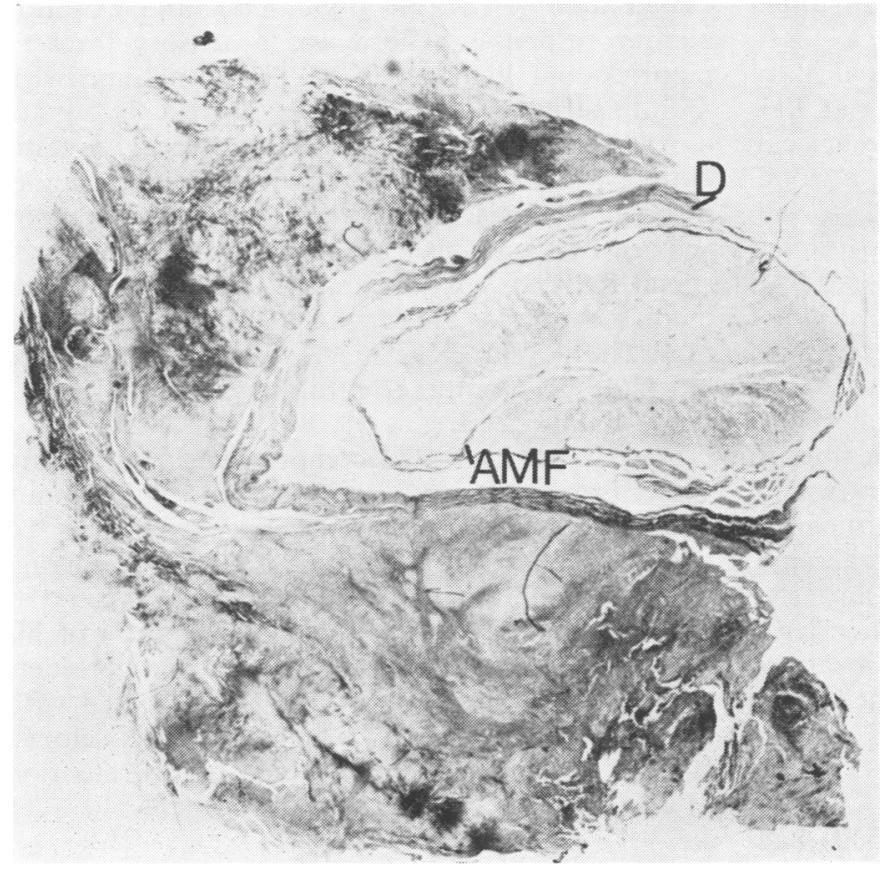

Fig. 1 Case 1. Compressed spinal cord surrounded by dura mater $(D)$ and extradural tumour. Note pallor of myelin staining of spinal cord. $A M F=$ anterior median fissure. Luxol fast blue, cresyl violet, $\times 5$.

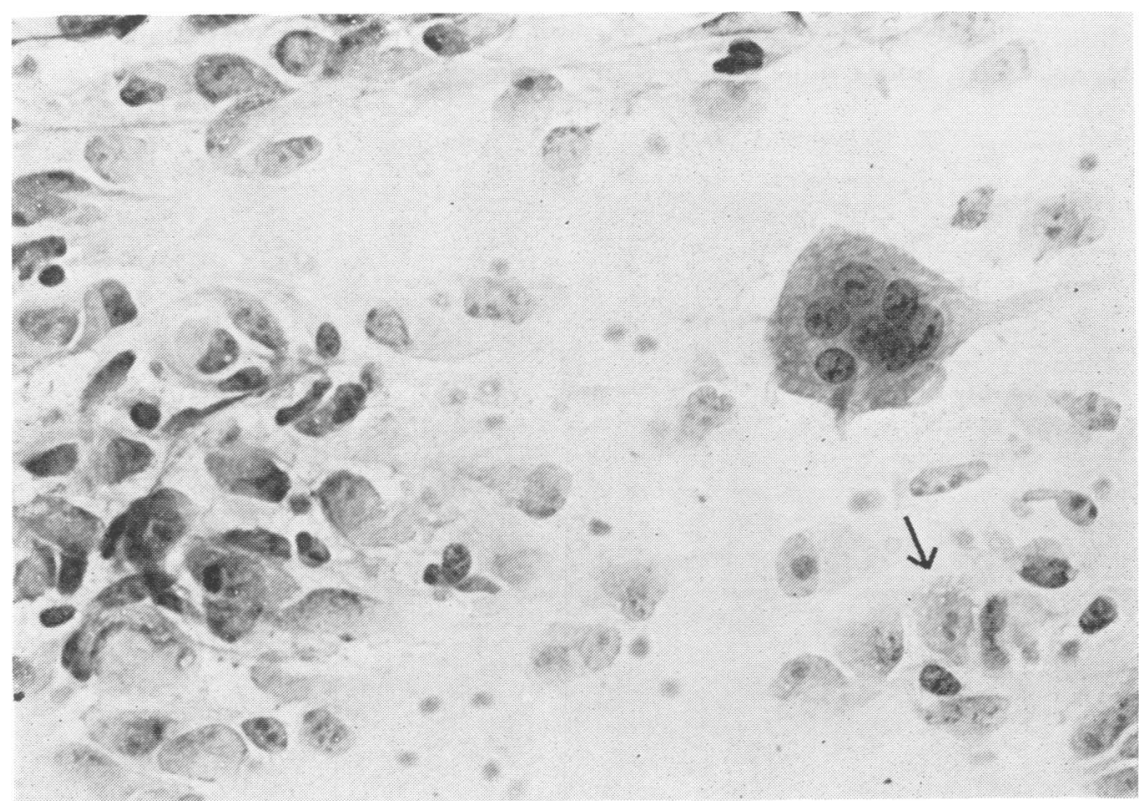

Fig. 2 Case 2. Smeared biopsy tissue showing giant multinucleate cell and other tumour cells, some with eccentric nuclei and vacuolated cytoplasm (arrow). Methylene blue, $\times 390$. 
panied by progressive weakness and numbness of her legs and difficulty initiating micturition. Routine haematology, biochemistry, and a chest radiograph were normal as were plain spinal films but a myelogram showed a complete block at T11 vertebra. She was transferred to the neurosurgical department where examination showed a total flaccid paraplegia with a sensory level to all modalities at T12 dermatome with no sacral sparing. The only other abnormality was extreme tenderness over the laminectomy scar. A decompressive laminectomy on 2 September 1977 revealed reddish tumour anterior to the theca and extending into the T11 vertebral body. The tumour was biopsied and shown to be a malignant fibrous histiocytoma (Fig. 2). The operation provided relief from pain but no recovery of neurological function, and she was referred for radiotherapy. Sensory symptoms and signs resolved, and she regained some proximal movement of her legs. More recently, however, there has been local recurrence of pain, and she is still confined to a wheelchair with no sphincter control.

CASE 3

This 46 year old man (NG, RI No. 699510) had a four week history of severe interscapular pain, hesitancy of micturition and constipation, and two days of weakness of both legs. He had lost $6.3 \mathrm{~kg}$ in weight over eight months.

Examination revealed tenderness over the upper thoracic spine, spasticity, and a mild weakness of upper motor neurone type in both lower limbs with exaggerated knee and ankle jerks and extensor plantar responses. There was a sensory level to pinprick and light touch to T6 dermatome with sacral sparing.

All biochemical and haematological investigations were normal as were a chest radiograph and intravenous pyelogram. Plain spinal radiographs showed destruction of the facet joints and a paraspinal mass at T6 vertebra. A bone scan showed increased uptake at $\mathrm{T} 1$ and $\mathrm{T} 2$ vertebrae, and a metrizamide myelogram revealed a complete block at T5-6 intervertebral space by an extradural mass.

On 3 August 1978 decompressive laminectomy showed an extensive extrathecal vascular tumour encircling the dura mater between $\mathrm{T} 3$ and $\mathrm{T} 6$ vertebrae. Biopsied material proved to be a malig nant fibrous histiocytoma (Fig. 3).

Postoperatively the patient had good use of his legs, and his bladder function improved considerably. He was free of pain. He was treated with local radiotherapy but two months later developed further weakness of his legs and acute retention of urine.

\section{Discussion}

It is now generally recognised that there is group of both benign and malignant neoplasms the latter with the ability to metastasise, derivee from the tissue histiocyte.

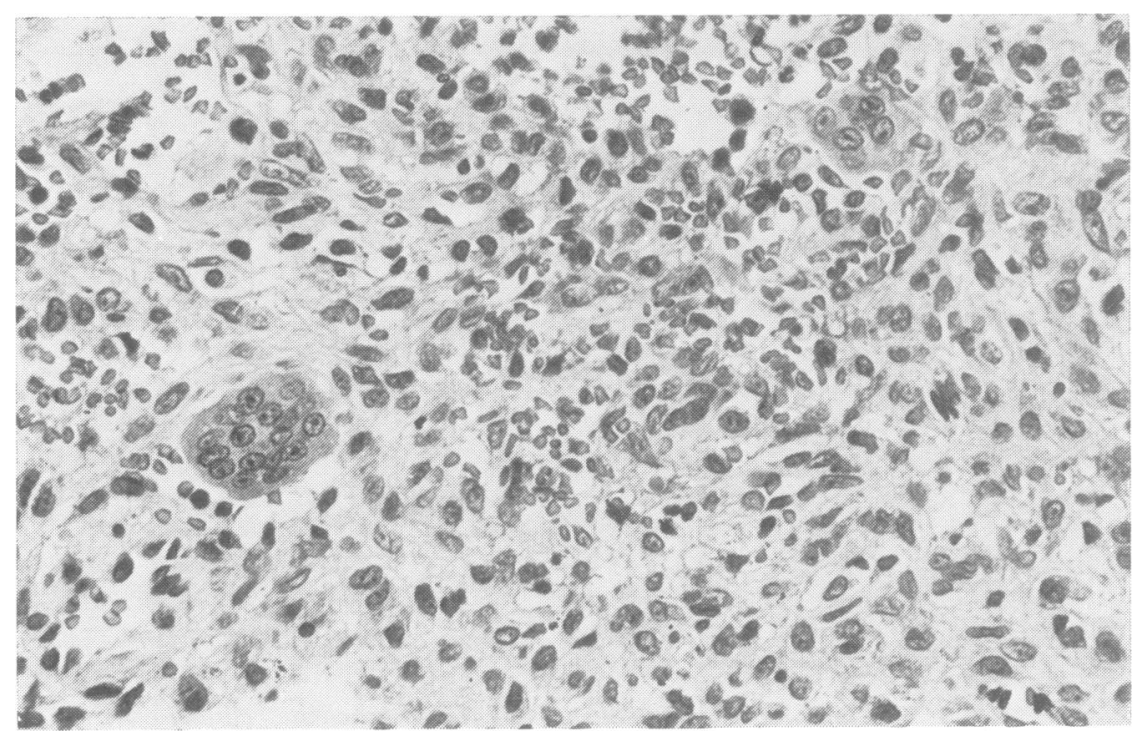

Fig. 3 Case 3. Section of tumour biopsy specimen showing cellular area with plump histiocytic cells and multinucleate cells. Haematoxylin and eosin, $\times 390$. 
Oberling (1935) described three cases of retroperitoneal xanthogranuloma having a large fibrocytic and/or histiocytic element together with an inflammatory cell infiltrate. These were thought to be benign inflammatory lesions but were described subsequently as having malignant characteristics (Waller et al., 1957; O'Brien and Stout, 1964; Pear, 1970; Rosas-Uribe et al., 1970). Soule and Enriquez (1972) suggested that they represented a deep form of atypical malignant fibrous histiocytoma.

The classification of these metastasising histiocytomas is complicated. Soule and Enriquez (1972) described four main types of growth divided on histological criteria into atypical fibrous histiocytoma, malignant fibrous histiocytoma, malignant histiocytoma, and epithelioid sarcoma. MacKenzie (1975), reviewing the published literature, described three histological groups-malignant fibrous histiocytoma, malignant histiocytoma, and giant cell tumour of soft tissues.

The fibrohistiocytic tumours comprising the first of these groups are characterised histologically by the presence of histiocytic or epithelioid cells, spindle cells, fibrogenesis, storiform pattern, multinucleated giant cells, inflammatory cells, especially lymphocytes, anaplasia of stromal cells, and mitotic figures. The malignant tumours are not clearly distinguishable from benign forms on histological grounds alone. A small number of these tumours arise in the retroperitoneal space, the remainder being widely distributed, chiefly in the deep soft tissues of the limbs.

In the series of Soule and Enriquez the mean age at which malignant fibrous histiocytoma occurred was 58 years with a peak in the seventh decade. Most of their cases had tumours sited in the lower limbs, two in the deep tissues of the trunk, and four were retroperitoneal. They described 33 cases of malignant fibrous histiocytoma of whom 13 died within five years -10 of metastases. Twelve were alive 5-27 years later, and of five who were followed up for less than five years, four had recurrences. No relation of survival to site of the lesion was documented. The overall five year survival rate was $64 \%$.

The mainstay of treatment appeared to be surgical removal of the lesion when possible, with radiotherapy directed at the tumour bed. Three patients had preoperative radiotherapy. The response of pulmonary secondaries to radiotherapy and to dactinomycin was variable.

Kellett and Dearnaley (1976) described two patients with malignant fibrous histiocytoma both of whom became paraplegic. The first presented with an epigastric mass, then developed evidence of generalised disease with skin metastases, and later involvement of cranial and spinal nerves with trigeminal neuralgia and paraplegia. The second became paraplegic and incontinent, and was found to have spinal nerve root infiltration at laminectomy. He later developed a testicular mass, biopsy of which provided the diagnosis. Each was treated with cytotoxic agents with little evidence of improvement, the first patient dying within three years of the onset of his symptoms. Kellett and Dearnaley emphasised the difficulty of making the diagnosis of malignant fibrous histiocytoma in the absence of an overt tumour, and noted that paraplegia secondary to nerve root infiltration may be a major feature.

Our three cases each presented with symptoms attributable to extradural spinal cord compression with severe local spinal pain and root pains followed by progressive paraparesis, sensory changes in the lower limbs, and sphincter disturbances. Two of the three had profound weight loss but in no case was there firm clinical, biochemical, haematological, or radiological evidence of malignancy or an infective focus outside the spinal column and immediate paraspinal tissues. The anatomical site and extent of the tumours were defined by plain spinal radiographs and myelography and the diagnosis made by biopsy of the extrathecal mass at decompressive laminectomy.

In all three cases the tumour mass was mainly anterior to the spinal cord and involved the vertebrae at the corresponding levels.

Clearly, the exact position and extent of these tumours, and particularly in the cases with paraspinal involvement, whether the mass is anterior or posterior to the spinal dura mater determines the feasibility of complete removal and therefore, presumably, the ultimate prognosis.

We feel that laminectomy in cases of extradural cord compression should be undertaken (1) to relieve pain, (2) to attempt complete removal of the compressive lesion, (3) to obtain a tissue diagnosis, and (4) to try to improve the neurological deficit.

As far as we can judge from our three cases presenting with spinal cord compression, pain relief is considerable after laminectomy but pain may recur with further tumour growth. Total removal is unrealistic, the tumour mass generally infiltrating the vertebral bodies and structures in front of the cord. Examination of small biopsy samples of these tumours from the extradural space may present considerable difficulty in distinguishing them from non-neoplastic granulo- 
matous conditions on the one hand and from lymphoreticular neoplasms on the other (Kellett and Dearnaley, 1976). We have found the appearances of smear preparations helpful in displaying the histiocytic nature of many of the cells, and the presence of multinucleate giant cells has been a prominent feature in our biopsy specimens. We would also emphasise the variation in histological appearance and degree of cellularity from one region of the tumour to another. The following features have all been present: histiocytic cells with abundant, sometimes foamy eosinophilic cytoplasm, spindle-shaped cells, variable amounts of collagen, multinucleate giant cells, and mitotic figures. A storiform pattern was not very conspicuous. Small areas of necrosis and calcification were present at necropsy examination of the tumour from case 1 . Neutrophil polymorphonuclear cell infiltration of the stroma, which has been described in some malignant fibrous histiocytomas (Kyriakos and Kempson, 1976), was not seen in our cases but scattered lymphocytes were present. The prognosis in terms of continuing neurological deficit after surgery followed by local radiotherapy appears poor. Two of our patients derived some benefit-power in their legs improved as did bladder function-but the beneficial effects lasted for only a few months. The role of cytotoxic agents has not yet been adequately assessed.

We would like to thank Mr C. B. T. Adams and $\mathrm{Mr}$ M. Briggs for permission to include patients under their care, and Mrs S. England for typing the manuscript.

\section{References}

Kellett, R. J., and Dearnaley, J. N. (1976). Malignant fibrous histiocytoma with diffuse spinal nerve involvement. Journal of Clinical Pathology, 29, 910 915.

Kyriakos, M., and Kempson, R. L. (1976). Inflammatory fibrous histiocytoma. An aggressive and lethal lesion. Cancer (Philadelphia), 37, 1584-1606.

MacKenzie, D. H. (1975). Miscellaneous soft tissue sarcomas. In Recent Advances in Pathology, pp. 183-216. Edited by C. V. Harrison and K. Weinbren. Churchill Livingstone: Edinburgh.

Oberling, C. (1935). Petroperitoneal xanthogranuloma. American Journal of Cancer, 23, 477-489.

O'Brien, J. E., and Stout, A. P. (1964). Malignant fibrous xanthoma. Cancer (Philadelphia), 17, 14451455.

Pear, B. L. (1970). The histiocyte in radiology-with case reports of retroperitoneal xanthogranuloma and malignant fibrous xanthoma. American Journal of Roentgenology, 110, 159-165.

Rosas-Uribe, A., Ring, A. M., and Rappaport, $\mathbf{H}$. (1970). Metastasizing retroperitoneal fibroxanthoma (malignant fibroxanthoma). Cancer (Philadelphia), 26, 827-831.

Soule, E. H., and Enriquez, P. (1972). Atypical fibrous $\stackrel{\rho}{-}$ histiocytoma, malignant fibrous histiocytoma $\Theta$ malignant histiocytoma and epithelioid sarcomar Cancer (Philadelphia), 30, 128-143.

Waller, J. I., Helwig, C. A., and Barbosa, E. (1957) Retroperitoneal xanthogranuloma associated withō visceral eosinophilic granuloma. Cancer (Phila? delphia), 10, 388-392. 